\title{
Ecological niche modeling and local knowledge predict new populations of Gymnocladus assamicus a critically endangered tree species
}

\author{
Shaily Menon ${ }^{1, *}$, Baharul I. Choudhury ${ }^{2,4}$, M. Latif Khan ${ }^{2}$, A. Townsend Peterson ${ }^{3}$ \\ ${ }^{1}$ Department of Biology, Grand Valley State University, Allendale, Michigan 49401, USA \\ ${ }^{2}$ Department of Forestry, North-Eastern Regional Institute of Science and Technology, Deemed University, \\ Nirjuli 791109 (Itanagar), Arunachal Pradesh, India \\ ${ }^{3}$ Biodiversity Institute, The University of Kansas, Lawrence, Kansas 66045, USA \\ ${ }^{4}$ Present address: Department of Biology, Concordia University, Montreal, Quebec H4B 1R6, Canada
}

\begin{abstract}
Gymnocladus assamicus is a critically endangered tree species endemic to northeastern India. Local inhabitants traditionally used this species for a variety of purposes. However, rapid population declines led to the species being considered extinct, until fieldwork in 2004 to 2007 identified 14 discrete populations of 1 to 7 trees each. To overcome constraints on field surveys imposed by the region's remoteness and rugged terrain, we targeted areas of further field inventories by estimating the potential distribution of the species. Ecological niche modeling enabled us to identify 26 sites which the model predicted to be highly suitable for the species' occurrence. We conducted rapid field surveys at 14 of the most accessible of these predicted sites. New populations were discovered at 5 of the 14 surveyed sites. In the remaining 12 less accessible sites, we interviewed residents from nearby villages and obtained indirect evidence of populations at 5 additional sites, which remain to be confirmed by direct field observations. This study demonstrates the utility of niche modeling as a tool for locating new populations of rare and endangered species. Our results will enhance ongoing efforts towards in situ conservation of this endangered species.
\end{abstract}

KEY WORDS: Endangered species - Gymnocladus assamicus • Ecological niche modeling . Population discovery $\cdot$ Field surveys $\cdot$ Local knowledge

\section{INTRODUCTION}

Locating populations of rare, endangered, and poorly known species is an important consideration in biodiversity conservation for assessing species' conservation status, and for developing effective strategies for in situ and ex situ conservation. Often, field surveys are constrained by rugged terrain, political unrest, poorly understood distributional ecology, and/or low population sizes with widely dispersed individuals. Ecological niche modeling (ENM) provides a powerful predictive framework for targeting areas for field surveys to locate additional populations. ENM combines known occurrence records with relevant environmental layers to estimate species' ecological requirements and potential geographic distributions (Guisan \& Zimmerman 2000, Soberón \& Peterson 2005). Such predictions help to narrow down the suite of possible occurrence sites for targeted field surveys, which otherwise may constitute a formidable time and labor sink with low probability of success. Previous applications of ENM for locating new populations of poorly known species have been described by Raxworthy et al. (2003), Bourg et al. (2005), Jarvis et al. (2005), and Ferreira de Siqueira et al. (2009).

Here, we apply 2 ENM techniques (Genetic Algorithm for Rule-set Prediction [GARP] and Maxent), along with a jackknife validation approach, to develop ENMs based on the few known occurrences of Gymnocladus assamicus, a critically endangered tree species 
endemic to northeastern India. The precarious status of this species results from external pressures of habitat loss and degradation, coupled with its small population size, poor dispersal and natural regeneration abilities, and separate male and hermaphrodite trees. We present results of field surveys and interviews with villagers based on the ENM predictions of highly suitable areas for the species' occurrence, and discuss implications of such studies for enhancing ongoing in situ and ex situ conservation efforts.

\section{MATERIALS AND METHODS}

Study site. Arunachal Pradesh, a state in northeastern India, includes a major portion of the southern slopes of the eastern Himalayas. This region contains India's richest terrestrial biodiversity and is home to nearly half of India's flowering plants and numerous endemic and endangered plant species (Rao \& Hajra 1986). The present study focused on Tawang and West Kameng, the 2 westernmost districts of Arunachal Pradesh $\left(26^{\circ} 54^{\prime}\right.$ to $28^{\circ} 01^{\prime} \mathrm{N}, 91^{\circ} 16^{\prime}$ to $\left.92^{\circ} 40^{\prime} \mathrm{E}\right)$. The region is bordered by Tibet to the north, Bhutan to the southwest, and the Indian state of Assam to the south.

Detailed field inventories had previously been carried out in 2004 to 2007 in the Dirang forest area $\left(27^{\circ} 18^{\prime}\right.$ to $27^{\circ} 34^{\prime} \mathrm{N}, 91^{\circ} 13^{\prime}$ to $92^{\circ} 15^{\prime} \mathrm{E}_{;} 1500$ to $2100 \mathrm{~m}$ ) in West Kameng, Arunachal Pradesh, northeastern India (Fig. 1). The forest is variously classified as eastern Himalayan wet temperate forest (Champion \& Seth 1968) or subtropical deciduous forest (Kaul \& Haridasan 1987). The area is mostly mountainous, covering 892 $\mathrm{km}^{2}$, and is surrounded by higher elevation terrain (2800 to $3400 \mathrm{~m}$ ) in the Bomdila and Tawang districts. The Dirang Forest Range was declared an 'Unclassed State Forest' by the state forest department; as most of the area is under the jurisdiction of local communities, it is also regarded as a community forest. The forest areas are exposed to diverse forms of anthropogenic and natural influences, such as logging, agricultural extension, human settlement, road construction, and landslides.

The dominant tribes (Monpa, Miji, Sherdukpen, Aka, and Khawa) of the surrounding areas are predominantly Buddhist. They depend on nature and plant and animal products, and follow certain rules and regulations that limit over-harvesting of natural resources.

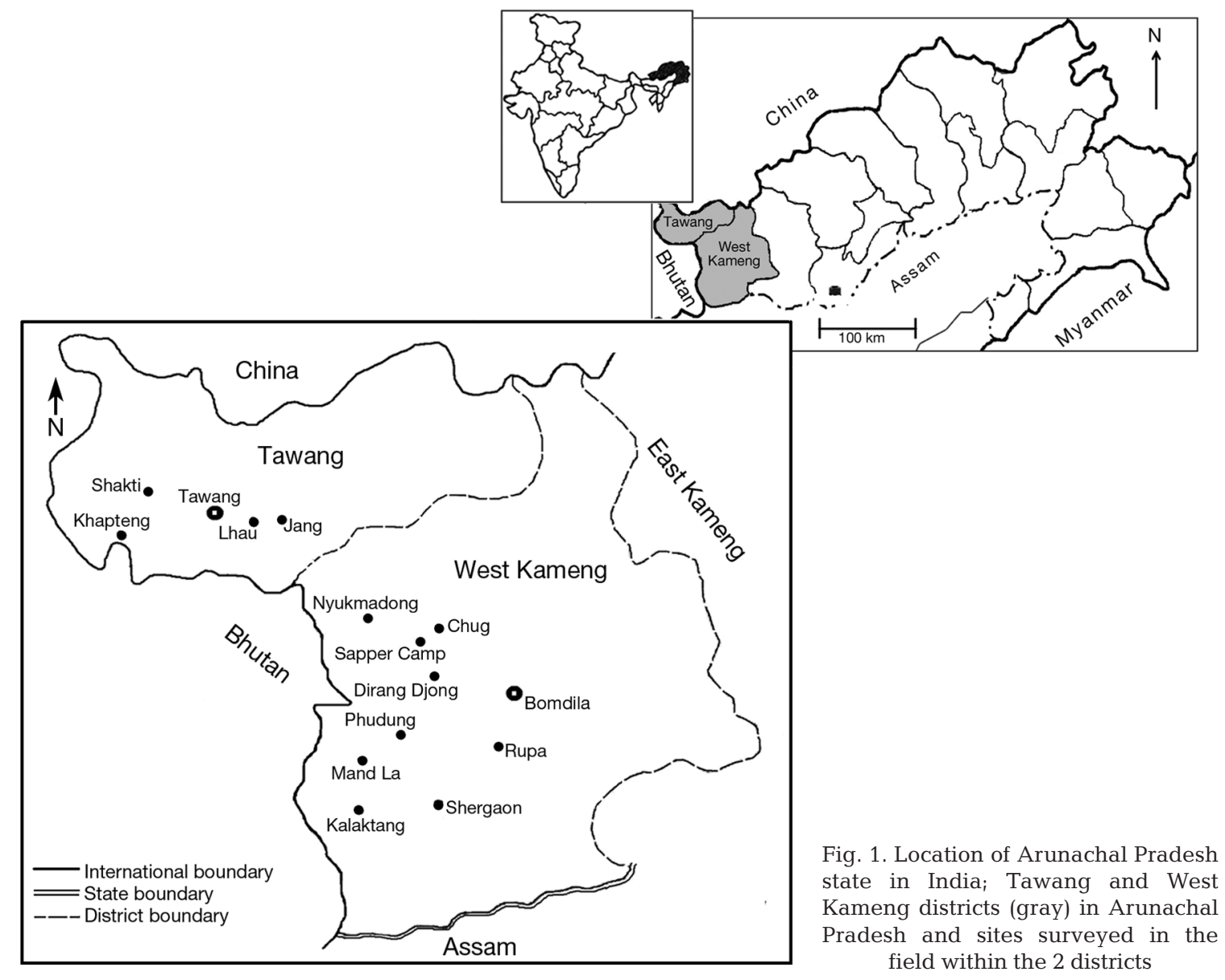


Study species. Gymnocladus is a small archaic genus of Leguminosae with an interesting global distribution pattern. According to the International Legume Database and Information Service (ILDIS), a total of 5 Gymnocladus species, viz. G. angustifolius (Gagnep.) J.E. Vidal, G. assamicus P.C. Kanjilal, G. burmanicus C.E. Parkinson, G. chinensis Baill., and G. dioica (L.) K. Koch are taxonomically accepted (Roskov et al. 2005). While the species G. dioica and G. angustifolius are reported to be restricted to North America and Vietnam respectively, the other 3 species are confined to the Indian-Chinese-Myanmar triangle (Sanjappa 2002).

Gymnocladus assamicus (Fig. 2a-e), a critically endangered tree species endemic to northeastern India (Choudhury et al. 2007a), is included in the priority list for a national recovery program in India (Ganeshaiah 2005). Local inhabitants have traditionally used this species for various purposes: pods are used as a substitute for soap/detergent to wash off sticky adhesives and to remove leeches from domestic animals, and roasted seeds are consumed as a substitute for groundnuts or coffee. Although the species was first described and documented from the Khasi Hills of Meghalaya in 1934 (Kanjilal et al. 1938), only 2 other records were available until recently, one from Arunachal Pradesh (Hajra et al. 1996) and the other from Nagaland (Sanjappa 2000). Detailed investigations (Choudhury et al. $2007 a$,b) conducted during 2004 to 2007, revealed that the population of G. assamicus is extremely small, with the total number of reproductive (hermaphroditic) individuals well below 50 .

The species exhibits poor natural regeneration owing to several extrinsic and intrinsic factors. It has been impacted by degradation of natural habitats as a result of agricultural expansion, construction of roads and houses in and around forest areas, overharvesting of mature pods for domestic use, and grazing (Choudhury et al. 2007a). Intrinsic constraints inhibiting regeneration include lack of dispersal and a hard, waxy seed coat. Furthermore, the species has co-occurring male and hermaphrodite individuals and may have an androdioecious reproductive system, a rare phenomenon in plants (Pannell 2002).

ENM. Detailed field inventories of natural populations of Gymnocladus assamicus from 2004 to 2007 , assisted by knowledge gathered from local inhabitants, identified 14 populations of 1 to 7 trees each. These 14 occurrence points were used as input data to train the niche model. All occurrence locations were georeferenced using geographic positioning system units accurate to between 10 and $100 \mathrm{~m}$.

Eleven remotely sensed layers from the NASAMODIS/Terra data set (spatial resolution $500 \times 500 \mathrm{~m}$; Justice et al. 1998) were used to characterize environments across the region. Six of the layers were $16 \mathrm{~d}$ com- posite images of the Enhanced Vegetation Index (EVI) from every second month in 2005, and 5 of the layers summarized the difference between each consecutive pair of the 6 EVI layers. EVI is calculated similarly to the Normalized Difference Vegetation Index (NDVI) from the visible and near-infrared light reflected by vegetation, and both indices are sensitive to photosynthetic activity (Huete et al. 1999). However, EVI corrects for distortion in reflected light as a result of particles in the air and ground cover below the vegetation, and is less easily saturated than NDVI over areas with high chlorophyll content, such as rainforests (Huete et al. 1999).

We used 2 evolutionary-computing approaches to develop ENMs and associated geographic predictions: GARP (Stockwell \& Peters 1999) and Maxent (Phillips et al. 2006). Both algorithms relate known occurrence points to sets of digital raster GIS data layers that describe relevant environmental parameters (in this case, the EVI data sets) to derive a model in the form of decision rules differentiating areas of suitable conditions from areas presenting unsuitable conditions. GARP uses a genetic algorithm to optimize predictive ability of models regarding independent suites of occurrence information, whereas Maxent uses the principle of maximum entropy to achieve the same end. In this application, we used default parameterization of both algorithms, except that a soft omission threshold of $20 \%$ was used in GARP, and a $50 \%$ random test percentage was used in Maxent. Because both algorithms are well described in the literature (Stockwell \& Peters 1999, Elith et al. 2006, Phillips et al. 2006, Peterson et al. 2007), we do not provide a detailed description of their function.

To provide a test of model predictability, we used the jackknife-based approach presented by Pearson et al. (2007), which is designed explicitly for situations of small sample size. In this approach, each known occurrence point is omitted sequentially, and models are developed based on the remaining points. An overall test of predictive ability, as compared to random expectations, is then assembled as the joint probability of achieving the observed predictive success, given proportional areas predicted to be present; this probability calculation is akin to a cumulative binomial probability, but with the underlying probability of success varying according to the proportional area predicted present in a given jackknife replicate. After confirming the significant predictive ability of both models, we combined them by rescaling them to the same 0 to 100 interval, and averaging them to produce a final prediction of landscape suitability.

Field surveys. We identified 26 discrete areas predicted by the ENM as having the highest probability of occurrence (i.e. most suitable) for Gymnocladus assamicus. To guide the field survey team, we generated 
maps demarcating the center and search radii of varying extents, for each of 26 areas that presented relatively contiguous areas that the models indicated as being suitable. The search radii ranged from 0.5 to 2.0 $\mathrm{km}$, corresponding to the extent of the high probability prediction at each site. The field survey team conducted rapid surveys over a $10 \mathrm{~d}$ period with the help of the maps and a GPS. Of the 26 predicted areas, 14 were relatively more easily accessible. The field survey team visited each of these 14 sites and searched for
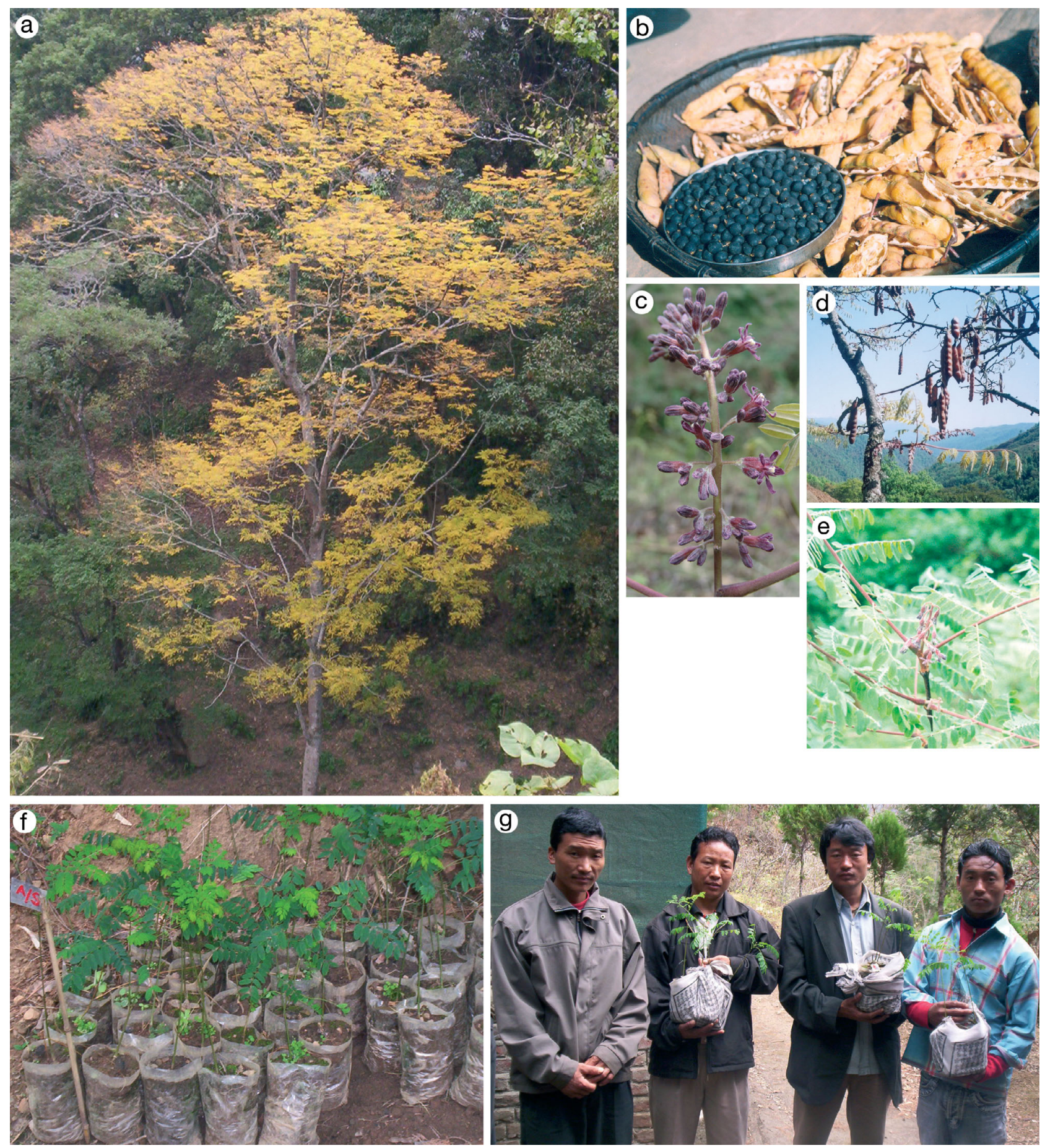

Fig. 2. Gymnocladus assamicus. (a) Individual tree, (b) harvested pods and seeds, (c) male inflorescence, (d) mature pods on trees, (e) hermaphrodite inflorescence, (f) seedlings ready for distribution from a greenhouse, and (g) distribution of seedlings among local villagers for planting in home gardens, farms, and wayside plantations as part of ongoing conservation strategies for this 


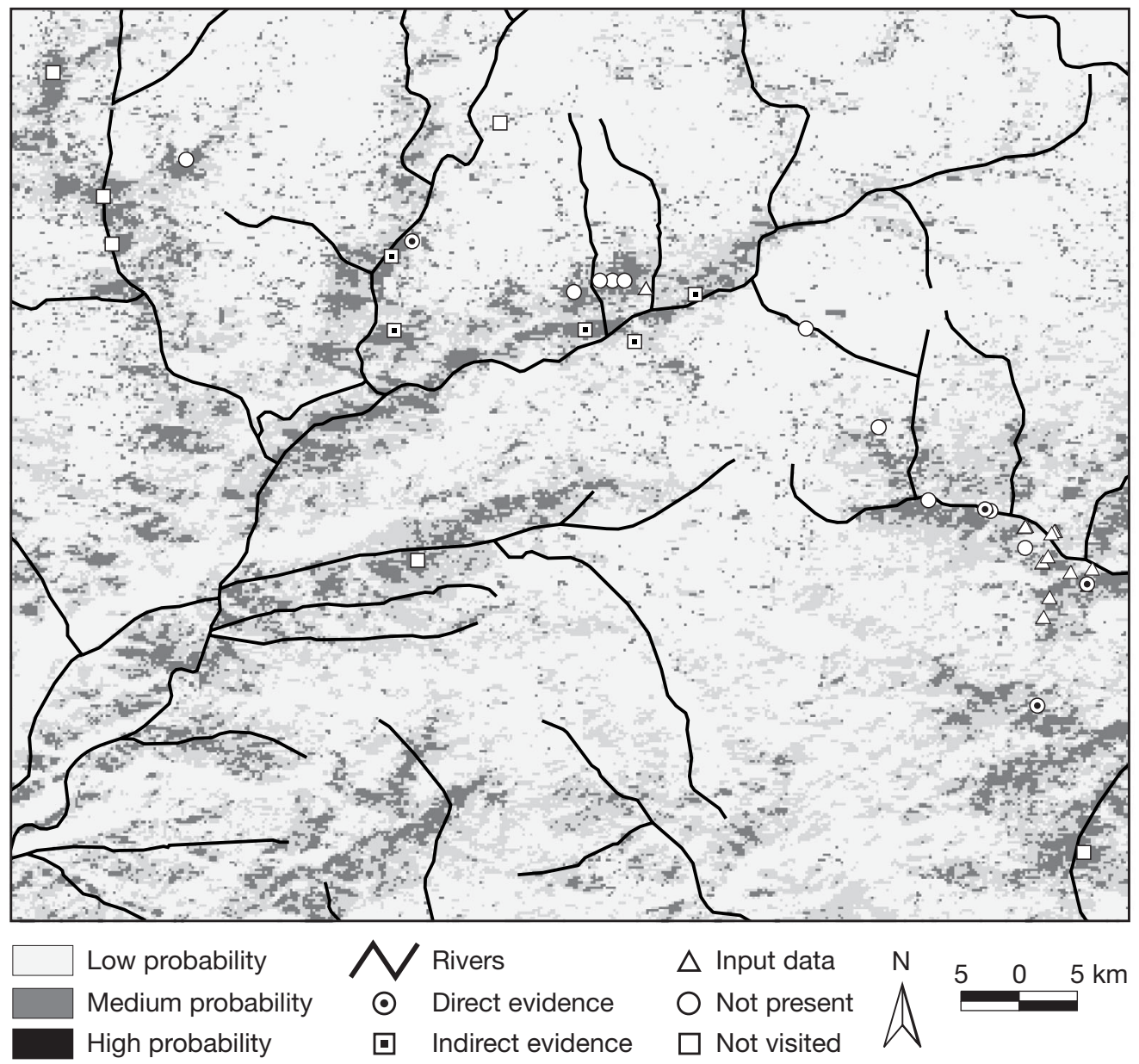

Fig. 3. Average of the 2 ecological niche modeling approaches for predicting the potential distribution of Gymnocladus assamicus. Darker areas represent regions with higher probability of the species' occurrence. Resolution of cells is $500 \times 500 \mathrm{~m}$. Direct evidence: G. assamicus individuals found in the field survey following model prediction; indirect evidence: occurrence of G. assamicus indicated by local villagers

G. assamicus individuals within the radius indicated by the niche model. The remaining 12 field sites could not be visited due to their inaccessibility. Instead, the field survey team interviewed residents from nearby villages to gather indirect evidence.

\section{RESULTS}

Both the GARP and Maxent ENM predictions identified similar areas across the study area. The jackknife tests of model validations confirmed that both predicted the species' occurrence significantly better than random expectations $(\mathrm{p}<0.05)$. Averaging the 2 predictions produced a predictive map that identified relatively restricted areas of the study region as having the highest suitability for the species (Fig. 3).

Fourteen of the 26 suitable sites were more easily accessible and were directly surveyed in the field.
New populations of Gymnocladus assamicus were discovered at 5 of these 14 sites; no individuals of this species were found in the remaining sites surveyed. Populations comprising 4 mature trees each were encountered in Sapper Camps 1 and 2 at the Chug predicted site. Both populations were on slopes on the bank of a small river. Although the trees were mature, flowering and fruiting were not observed during the field survey. Two fruiting trees were found growing between small hillocks in the Dirang Dzong (Phadam) predicted site. One mature tree was discovered at each of the Shakti and Phudung (Wangkethanka) sites in valleys near small streams.

Interviews with residents from nearby villages indicated the likely presence of additional individuals at 5 of the 12 sites that were relatively less accessible. These potential occurrences at Tawang, Kapteng, Shakti, Lhau, Jang, and Kanglar sites are unconfirmed, pending further field surveys for verification. 


\section{DISCUSSION}

Plant species dominate lists of rare and endangered species, and their survival depends on in situ protection and management (Ellstrand \& Elam 1993). Conservation of rare plants is thus a daunting prospect, given the large numbers of species requiring attention globally and the unique problems they pose (Falk \& Holsinger 1991). Such taxa often exist as relatively small populations (Holsinger \& Gottlieb 1989) and may be subject to inbreeding effects, population bottlenecks, and unpredictable fluctuations in allelic frequencies owing to genetic drift (Ellstrand \& Elam 1993, Fenster \& Dudash 1994).

This study illustrates the potential of ENM in enabling and improving endangered species research, permitting identification of additional populations of rare and poorly known species via rapid field surveys, targeted and guided by niche model predictions. In this study, we used the case of Gymnocladus assamicus, a critically endangered tree species with both economic and ecological significance, to illustrate how this approach can be implemented. Our approach combined 2 ENM techniques with a jackknife validation approach to assess the effectiveness of the predictive models. We demonstrate that models generated with small numbers of known occurrence points can be effective in predicting high probability (suitable) areas of species occurrence (distribution). This validation approach has demonstrated considerable predictive power of models generated with scarce locality records with respect to their potential for the discovery of new species and populations (Pearson et al. 2007).

More detailed field surveys, such as in areas where only indirect evidence of the species' presence was recorded, will likely uncover additional populations and individuals of this species. Still, in spite of our discoveries, the numbers and population size of Gymnocladus assamicus remain extremely small. Given the small number of mature trees, continuous monitoring and active protection of existing populations is of the utmost importance to ensure the species' survival (Choudhury et al. 2007a,b); therefore, all known populations should be protected and preserved. For longterm conservation of germ plasm, seeds from each plant located in the original surveys were deposited to the ARIS cell of the National Bureau of Plant Genetic Resources, New Delhi, India (IC no. IC-551620, B. I. Choudhury \& M. L. Khan unpubl. data).

Furthermore, conservation efforts should be aimed at maintaining the vigor of populations, now that more populations have been identified. Given the species' demographic characteristics (Choudhury et al. 2007a), seedling and sapling populations do not contribute to the maintenance of natural regeneration stock. As such, introduction and reintroduction of the species in suitable ecological habitats may be an important option to restore Gymnocladus assamicus populations, another point at which ENM can be useful: niche models can be useful in identifying suitable sites for such efforts (Martínez-Meyer et al. 2006). Supplementary regeneration to restore populations could be an additional adaptive strategy to combat decline in G. assamicus populations (Choudhury et al. 2007a). This goal may be achievable by introducing nurserygrown seedlings to compensate for lack of natural recruitment.

Other conservation strategies include increasing awareness among local people about the threat to the species from habitat degradation and overharvesting of mature pods, and encouraging protection of existing reproducing individuals and sustainable harvest of mature pods. As an initial step, several awareness meetings have been conducted to involve local communities in conservation of existing populations (B. I. Choudhury \& M. L. Khan unpubl. data). As a part of these conservation initiatives, nursery-grown seedlings have been distributed to local people to increase populations of Gymnocladus assamicus in natural habitats (Fig. 2f,g, and B. I. Choudhury \& M. L. Khan unpubl. data). They have been encouraged to plant the seedlings in home gardens, in traditional agricultural land, and in wayside plantations, which are generally well protected (Choudhury et al. $2007 a, b)$.

Acknowledgements. We thank P. K. Dutta (WWF-India), B. Basumatary, S. Khandu, J. Tsering, and others for assistance during field surveys. Financial assistance was provided to M.L.K. from the Department of Science and Technology, New Delhi (Sanction no. SR/SO/PS-16/2002).

\section{LITERATURE CITED}

Bourg NA, McShea WJ, Gill DE (2005) Putting a cart before the search: successful habitat prediction for a rare forest herb. Ecology 86:2793-2804

Champion HG, Seth SK (1968) A revised survey of the forest types of India. Publication Division, Government of India Press, New Delhi

Choudhury BI, Khan ML, Arunachalam A, Das AK (2007a) Ecology and conservation of the critically endangered tree species Gymnocladus assamicus in Arunachal Pradesh, India. Res Lett Ecol 2007:59282 doi:10.1155/2007/59282

Choudhury BI, Khan ML, Arunachalam A, Das AK (2007b) Population and conservation of Gymnocladus assamicus U. N. and P. C. Kanjilal; a critically endangered tree species in a humid subtropical forest in Arunachal Pradesh, India. Curr Sci 93:1489-1491

> Elith J, Graham CH, Anderson RP, Dudik M and others (2006) Novel methods improve prediction of species' distributions from occurrence data. Ecography 29:129-151 
Ellstrand NC, Elam DR (1993) Population genetic consequences of small population size: implications for plant conservation. Annu Rev Ecol Syst 24:217-242

Falk DAI, Holsinger KE (eds) (1991) Genetics and conservation of rare plants. Oxford University Press, New York, NY

Fenster CB, Dudash MR (1994) Genetic considerations for plant population restoration and conservation. In: Bowles ML, Whelan CJ (eds) Restoration of endangered species: conceptual issues, planning and implementation. Cambridge University Press, Cambridge, p 34-62

Ferreira de Siqueira, M, Durigan G, de Marco P Júnior, and Peterson AT (2009) Something from nothing: using landscape similarity and ecological niche modeling to find rare plant species. J Nat Conserv 17:25-32

Ganeshaiah KN (2005) Recovery of endangered and threatened species: developing a national priority list of plants and insects. Curr Sci 89:599-600

Guisan A, Zimmerman NE (2000) Predictive habitat distribution models in ecology. Ecol Model 135:147-186

Hajra PK, Verma DM, Puri GS (eds) (1996) Materials for the flora of Arunachal Pradesh, Vol 1. Botanical Survey of India, Calcutta

Holsinger KE, Gottlieb LD (1989) The conservation of rare and endangered plants. Trends Ecol Evol 4:193-194

Huete A, Justice C, van Leeuwen W (1999) MODIS vegetation index (MOD 13) algorithm theoretical basis document, Ver 3. Available at http://modis.gsfc.nasa.gov/data/ atbd/atbd_mod13.pdf

> Jarvis A, Williams K, Williams D, Guarino L, Caballero P, Mottram G (2005) Use of GIS for optimizing a collecting mission for a rare wild pepper (Capsicum flexuosum Sendtn.) in Paraguay. Genet Resour Crop Evol 52:671-682

Justice CO, Vermote E, Townshend JRG, Defries R and others (1998) The Moderate Resolution Imaging Spectroradiometer (MODIS): land remote sensing for global change research. IEEE Trans Geosci Rem Sens 36:1228-1249

Kanjilal UN, Kanjilal PC, Das A (1938) Flora of Assam, Vol 2. Government of Assam, Shillong

Kaul RN, Haridasan K (1987) Forest types of Arunachal

Editorial responsibility: Hans Juergen Boehmer, Munich, Germany
Pradesh — a preliminary study. J Econ Taxon Bot 9:379-389

Martínez-Meyer E, Peterson AT, Servín J, Kiff LF (2006) Ecological niche modelling and prioritizing areas for species reintroductions. Oryx 40:411-418

Pannell JR (2002) The evolution and maintenance of androdioecy. Annu Rev Ecol Syst 33:397-425

> Pearson RG, Raxworthy C, Nakamura M, Peterson AT (2007) Predicting species' distributions from small numbers of occurrence records: a test case using cryptic geckos in Madagascar. J Biogeogr 34:102-117

Peterson AT, Papefl M, Eaton M (2007) Transferability and model evaluation in ecological niche modeling: a comparison of GARP and Maxent. Ecography 30:550-560

> Phillips SJ, Anderson RP, Schapire RE (2006) Maximum entropy modeling of species geographic distributions. Ecol Model 190:231-259

Rao RR, Hajra PK (1986) Floristic diversity of the eastern Himalaya - in a conservation perspective. Proc Indian Acad Sci (Animal/Plant Sci) Suppl:103-125

Raxworthy C, Martínez-Meyer E, Horning N, Nussbaum R, Schneider G, Ortega-Huerta M, Peterson AT (2003) Predicting distributions of known and unknown reptile species in Madagascar. Nature 426:837-841

Roskov YR, Bisby FA, Zarucchi JL, Schrire BD, White RJ (eds) (2005) ILDIS World Database of Legumes: draft checklist, version 10. ILDIS, University of Reading, Reading

Sanjappa M (2000) Checklist of the Leguminosae of South Asia. ILDIS World Database of Legumes Ver 6.0 for the 4th Int Legume Conf, Canberra. Available at: www.ildis.org/

Sanjappa M (2002) Gleditsia L. and Gymnocladus Lam. (Leguminosae-Caesalpinioideae) in India. In: Rao RR (ed) Advances in legume research in India. Bishen Singh Mahendra Pal (BSMP) Singh Publishing, Dehradun, p 27-34

Soberón J, Peterson AT (2005) Interpretation of models of fundamental ecological niches and species' distributional areas. Biodivers Inf 2:1-10

Stockwell DRB, Peters DP (1999) The GARP modelling system: problems and solutions to automated spatial prediction. Int J Geogr Inf Syst 13:143-158

Submitted: August 4, 2008; Accepted: February 17, 2010 Proofs received from author(s): April 13, 2010 